\title{
Mesenteric Panniculitis (MP) in CT - A Predictor of Malignancy?
}

\section{Mesenteriale Pannikulitis (MP) im CT-Schnittbild - Ein Prädiktor für ein Malignom?}

Authors

Affiliations
F. Scheer ${ }^{1}$, P. Spunar ${ }^{2}$, P. Wiggermann ${ }^{3}$, C. Wissgott ${ }^{1}$, R. Andresen ${ }^{1}$

Institute of Diagnostic and Interventional Radiology/Neuroradiology, Westkuestenklinikum Heide, Academic Teaching Hospital of the Universities of Kiel, Luebeck and Hamburg, Heide, Germany

2 Radiology Center Peine, Germany

Department of Radiology, University Hospital Regensburg, Germany
Key words

- abdomen

- mesentery

- CT spiral

received $\quad 14.2 .2016$

accepted 15.5.2016

Bibliography

Dol http://dx.doi.org/

10.1055/s-0042-110100

Published online: 16.8.2016

Fortschr Röntgenstr 2016; 188:

926-932 @ Georg Thieme

Verlag KG Stuttgart · New York .

ISSN 1438-9029

\section{Correspondence}

Dr. Fabian Scheer

Institute of Diagnostic and Interventional Radiology/

Neuroradiology,

Westküstenklinikum Heide, Academic Teaching Hospital of the Universities of Kiel, Lübeck and Hamburg

Esmarchstraße 50

25746 Heide

Germany

Tel.: ++49/4 81/785703595

Fax: ++ 49/481/7852409

FScheer@wkk-hei.de

\section{Abstract \\ $\nabla$}

Purpose: The exact etiology of mesenteric panniculitis (MP) is still unknown and has been discussed in relation to different causes. The aim of this retrospective study was to evaluate a coherence between MP and malignancy.

Materials and Methods: Retrospective analysis of consecutive CT abdomen examinations of 5595 patients in terms of MP over a period of 3 years was performed. To make the diagnosis of MP, three of five typical signs were obligatory: hyperdense mass lesion with intercalated nodules, a "fat-ring sign" or halo sign, a hyperdense pseudocapsule and displacement of bowel loops. The patient cohort (mean age: 64.7 years) consisted of 1974 (35.2\%) patients with histologically confirmed cancer and 3621 patients $(64.8 \%)$ without known underlying oncological disease.

Results: A total of 143 cases were diagnosed with MP (2.55\%). The average age of patients was 69.9 years with a male to female ratio of $2: 1$. In this group oncological disease was confirmed in 107 patients (74.8\%). In 36 patients with MP (25.2\%), no malignancy was present. In the group of patients with an underlying oncological disease, the prevalence of MP was $5.42 \%$ and was significantly higher $(\mathrm{p}<0.005)$ than in the patients with MP and without an oncological disease. The highest prevalence of MP (29 cases) was observed in non-Hodgkin lymphoma (22.6\%). The statistically calculated risk of a tumor disease in this collective is about 5 times higher if MP was demonstrated $(\mathrm{p}<0.001)$.

Conclusion: Based on the data of the collective, the risk of malignancy is five times higher in the presence of MP than in an inconspicuous mesentery. MP seems to frequently occur with non-Hodgkin lymphoma. MP can be seen on the basis of typical morphological features on the CT image. MP must be differentiated from a wide range of benign and malignant diseases of the mesentery.

Key points:

- Mesenteric panniculitis can be diagnosed with $\mathrm{CT}$.

- In the case of accidentally diagnosed mesenteric panniculitis, a possible malignant cause should be ruled out in the differential diagnosis.

Citation Format:

- Scheer F, Spunar P, Wiggermann P et al. Mesenteric Panniculitis (MP) in CT - A Predictor of Malignancy?. Fortschr Röntgenstr 2016; 188: 926-932

\section{Zusammenfassung}

$\nabla$

Ziel: Die genaue Ätiologie einer Mesenterialen Pannikulitis (MP) ist bis heute nicht genau geklärt und wurde im Zusammenhang mit unterschiedlichen Ursachen diskutiert. Primärer Endpunkt dieser retrospektiven Arbeit war die Evaluation einer Kohärenz zwischen einer MP und einer malignen Grunderkrankung.

Material und Methodik: Retrospektive Analyse konsekutiver CT-Abdomenuntersuchungen von 5595 Patienten über einen Zeitraum von 3 Jahren hinsichtlich einer MP. Für die Diagnose der MP waren drei von fünf typischen Zeichen obligat: Erhöhte Dichte des Mesenteriums mit eingelagerten Noduli, ein „Fat-ring-Sign“ bzw. Fett-Halo, eine Ausbildung einer Pseudokapsel und Verdrängung der Darmschlingen. Das Patientenkollektiv (Durchschnittalter 64,7 Jahre) bestand aus 1974 (35,2\%) Patienten mit histologisch gesichertem Tumor und $3621 \mathrm{~Pa}-$ tienten (64,8\%) ohne bekannte onkologische Grunderkrankung.

Ergebnisse: Im gesamten Patientenkollektiv wurden143 Fälle mit einer MP diagnostiziert (2,55\%). 
Das Durchschnittsalter der Patienten betrug 69,9 Jahre bei einem Verhältnis des männlichen zum weiblichen Geschlecht von 2:1. In dieser Gruppe war bei 107 Patienten $(74,8 \%$ ) eine onkologische Erkrankung gesichert. Bei 36 Patienten mit einer MP $(25,2 \%)$ lag kein Malignom vor. Im Patientenkollektiv mit einer onkologischen Grunderkrankung betrug die Prävalenz der MP $5,42 \%$ und war somit signifikant höher $(\mathrm{p}<0,005)$ als in der Patientengruppe mit MP ohne onkologische Erkrankung. Die höchste Prävalenz der MP mit 29 Fällen wurde beim Non-Hodgkin-Lymphom beobachtet (22,6\%). Das statistisch berechnete Risiko für eine Tumorerkrankung liegt in diesem Kollektiv ca. fünfmal so hoch, falls eine MP nachgewiesen wurde $(p<0,001)$.

Schlussfolgerung: Bei Vorliegen einer MP kann aus den Daten dieses Kollektivs von einem etwa fünfmal so hohen Risiko für eine maligne Erkrankung ausgegangen werden als bei einem unauffälligen Mesenterium. Dabei scheint eine MP gehäuft bei einem NonHodgkin-Lymphom aufzutreten. Die MP ist im CT-Bild durch typische morphologische Merkmale erkennbar und muss differenzialdiagnostisch zu einem breiten Spektrum benigner und maligner Erkrankungen des Mesenteriums abgegrenzt werden.

\section{Introduction}

Mesenteric panniculitis (MP) is a rare inflammatory disease of the adipose tissue of the mesentery with specific morphological signs in computed tomography (CT) [1]. MP is a type of sclerosing mesenteritis which is an IgG4-related sclerosing disease (ISD) [2]. The disease is characterized by necrosis, inflammatory infiltration, and fibrosis of the mesenteric adipose tissue, with these three dominant processes occurring to different degrees $[3,4]$. The preferred location is the root of the small bowel mesentery $[5,6]$. Inflammatory, autoimmune, postoperative, and malignant causes are discussed with respect to etiology [3, 5, 6]. Although there are no specific clinical symptoms of MP, generalized abdominal pain is common. As a result of the broad use of CT, MP is increasingly diagnosed as an incidental finding in asymptomatic patients. CT is an important examination method for diagnosing MP. MP presents with specific signs on a CT image. In addition to an increase in the density of the mesentery with intercalated nodules, a "fat-ring sign" as a halo around vessels, formation of a pseudocapsule and displacement of bowel loops are signs of MP [7, 8]. According to the literature, the prevalence of MP is between $0.16 \%$ and $2.4 \%$ $[6,7,9,10]$. MP occurs in every age group, but primarily in 6 th to 7 th decade of life. The male to female ratio is $2: 1$ [6, 11]. The differential diagnoses of MP are a broad spectrum of inflammatory, infectious, neoplastic, vascular-ischemic and idiopathic diseases [12]. In particular, NHL must be ruled out in the case of neoplasia [13]. The primary goal of this retrospective study was to evaluate a coherence between MP and an underlying malignant disease.

\section{Materials and Methods}

$\nabla$

The study included 5595 multislice computed tomography (MSCT) abdomen examinations acquired between January 2010 and December 2013 (3004 data sets from a tertiary care hospital and 2591 from a radiology practice). The inclusion criterion for the RIS-based data search was all CT abdo- men examinations with a scanning field from the diaphragm to the lower abdomen so that visualization of the entire root of the mesentery was ensured. Follow-up examinations, examinations of the upper abdomen, and CT scans of the pelvis were not included. The gender ratio in the patient population was almost equal: 2863 women $(51 \%)$ and 2732 men (49\%). The average age was $64.7+/-15.13$ years (age range: 4-100 years). The database search was performed in the RIS/PACS system with a search filter. The CT data sets were blinded using identification numbers and were retrospectively and systematically examined for MP by a radiology specialist with multi-year experience in abdominal CT. All CT scans were acquired with an MSCT unit (Brilliance CT 16, Philips Healthcare und Activion CT 16, Toshiba) according to standard clinical protocols. Images were acquired with an axial scan orientation and in the craniocaudal direction with a collimation of $16 \times 1.5 \mathrm{~mm}$, a rotation time of $0.75 \mathrm{~s}$, and a pitch factor of 0.94. Automatic tube current modulation. Standard coronal and sagittal reconstructions in the soft-tissue window (W: 350, C: 50 ) with a reconstruction interval of $5 \mathrm{~mm}$ were generated from the MSCT data sets. $90 \%$ of the examinations (5053) were examined with an i.v. contrast agent. No i. v. contrast agent was used in $10 \%$ of the examinations (542). 5595 MSCT data sets were thoroughly examined for the typical signs of MP. At least three of five criteria had to be present for a diagnosis of MP. In addition to a diffuse increase in the density of the mesentery with intercalated nodules and a consecutive space-occupying effect resulting in displacement of the adjacent bowel loops, a halo around the mesenteric vessels and possible capsule formation had to be present. The tumoral pseudocapsule is visualized as a narrow band of compression and limits the process with respect to normal mesenteric adipose tissue ( $\bullet$ Fig. 1 , - Table 1). Patients were first evaluated with respect to known tumor diseases. Statistical evaluations were performed with IBM SPSS Statistics (Version 23, Chicago, IL, USA) and EXCEL 2010 (Microsoft). Data were presented as mean \pm standard deviation (SD). Multivariate regression analyses including the hazard ratios were performed. The nonparametric Mann-Whitney U-test for independent variables and the Wilcoxon signed rank test for dependent variables were used.

\section{Results \\ $\nabla$}

143 of 5595 retrospectively examined MSCT data sets (2.55\%) showed typical signs of MP. 87 data sets came from the tertiary care hospital and 56 MSCT data sets from the radiological practice. The male to female ratio was approx. $60 \%$ to $40 \%$ (90/143 male, 53/143 female). The average age was $69.9+/-10.65$ years (range: $32-92$ years). 3 signs of MP could be reliably diagnosed in $38 / 143$ cases (26.6\%), 4 signs in 54/143 (37.8\%), and all signs in 51/143 patients (35.8\%) on computed tomography ( $\odot$ Fig. 2). An increase in the density of the mesentery with mean values of $-67 \mathrm{HU}+/-18 \mathrm{HU}$ was seen in all patients (143) in our cohort. Intercalated nodules with a mean cross-sectional diameter of $8 \mathrm{~mm}$ $(+/-4 \mathrm{~mm})$ were detected in 142 patients $(97.2 \%)$. A spaceoccupying effect with displacement of the adjacent bowel loops was diagnosed in $78 \%$ of cases (111), formation of a 


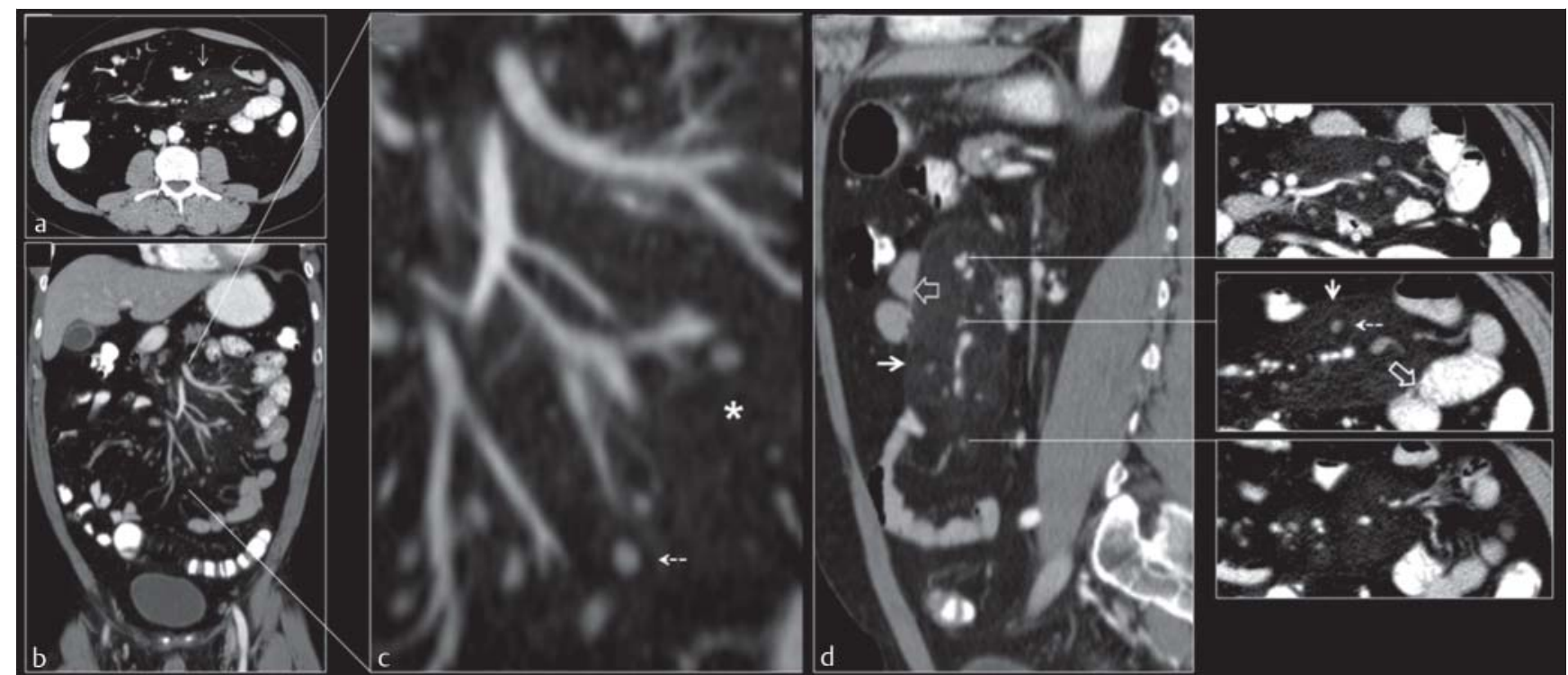

Fig. 1 Typical imaging of MP: a MP represents a delicate pseudocapsule (arrow $2 \mathrm{~mm}$ ) and an increase in density and intercalated nodules $(4 \mathrm{~mm})$. The coronal reformation offers a good overview of the number and size of nodules $\mathbf{b}$. In the magnification the "fat-ring sign" around the nodule is de-

marcated (c, dotted arrow). The sagittal reconstruction shows the craniocaudal diameter of the MP and the space-occupying component $\mathbf{d}$. The block arrows show the space-occupying effect $\mathbf{d}$. The pseudocapsule limits the MP. An infiltration of adjacent structures must be missing.
Table 1 Diagnostic criteria of MP in computed tomography. A diagnosis of MP is likely if at least three criteria are met.

\section{morphological criteria of MP in computed tomography}

diffuse increase in density of mesenteric adipose tissue with a ground-glass appearance

intercalated nodules

pseudocapsule

"fat-ring sign"

space-occupying effect with displacement or compression of

bowel loops

\section{CT diagnostic criteria of MP at all patients $(n=143)$}

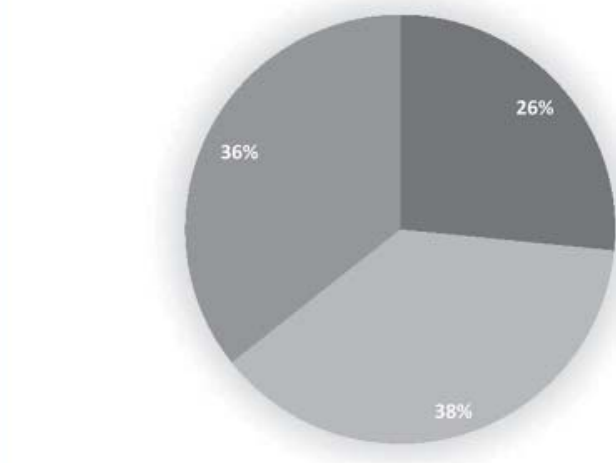

- 3 fulfilled criteria ( $n=38$ )

4 fulfilled criteria ( $n=54)$

- 5 fulfilled criteria ( $n=51)$

Fig. 2 Frequency of the criteria of MP based on the total collective with MP.

pseudocapsule in $70 \%$ of cases (100), and a halo sign in 86 patients (60\%) ( $\bullet$ Fig. 3).
A tumor disease was confirmed in 1974/5595 patients (35.2\%). The average age in this group was $67.6+/-12.55$ years (age range: 4-100 years). The gender ratio was almost 1:1 (988 men, 986 women). The tumor entities and the frequency distribution are shown in 0 Table 2 . A histopathologically confirmed oncological disease with a maximum in the case of lymphoma was present in 107 of the 143 patients with $\mathrm{MP}(74.8 \%)$ at the time of CT evaluation. In 36/143 patients (25.2\%) with diagnosed MP, there was no known tumor disease in the medical history. The average age of these patients was $69.8+/-11.13$ years (age range: 49 - 92 years). The gender ratio was almost equal $19 / 36$ men (52.8\%) and $17 / 36$ women (47.2\%).

In our patient population MP was significantly more frequently associated with an underlying oncological disease $(\mathrm{p}<0.005)$. The greatest prevalence for MP was seen in the group with lymphoma diseases. $22.65 \%$ of patients with confirmed lymphoma disease presented with MP. Frequency distribution of the diagnostic criteria of MP on the MSCT image shows a tendency toward MP without an associated tumor in our cohort ( $\odot$ Fig. 4, 5). Therefore, the criteria of increased density and intercalated nodules in the MP cohort with and without tumor disease were not significantly different. The mean cross-sectional diameter of the nodules in the entire cohort was $8 \mathrm{~mm}(+/-4 \mathrm{~mm})$. The space-occupying component was seen slightly more frequently in the non-oncological group than in the oncological group (81\% (29/36) vs. $77.6 \%(83 / 107))$. A typical halo sign was diagnosed in $62 / 107$ patients (58\%) in the oncological group and in 25/36 patients (69\%) in the non-oncological group. Pseudocapsules were seen more frequently in the non-oncological group (86\% (31/36)) than in the oncological group (64\% (69/107)) ( $\mathbf{~ F i g . 6 ) . ~ A c c o r d i n g ~ t o ~ t h e ~ r e t r o s p e c t i v e ~ a - ~}$ nalysis of our data, the presence of a tumor disease is 5211 (CI 95\% 3549-7651) times more likely in the case of MP 


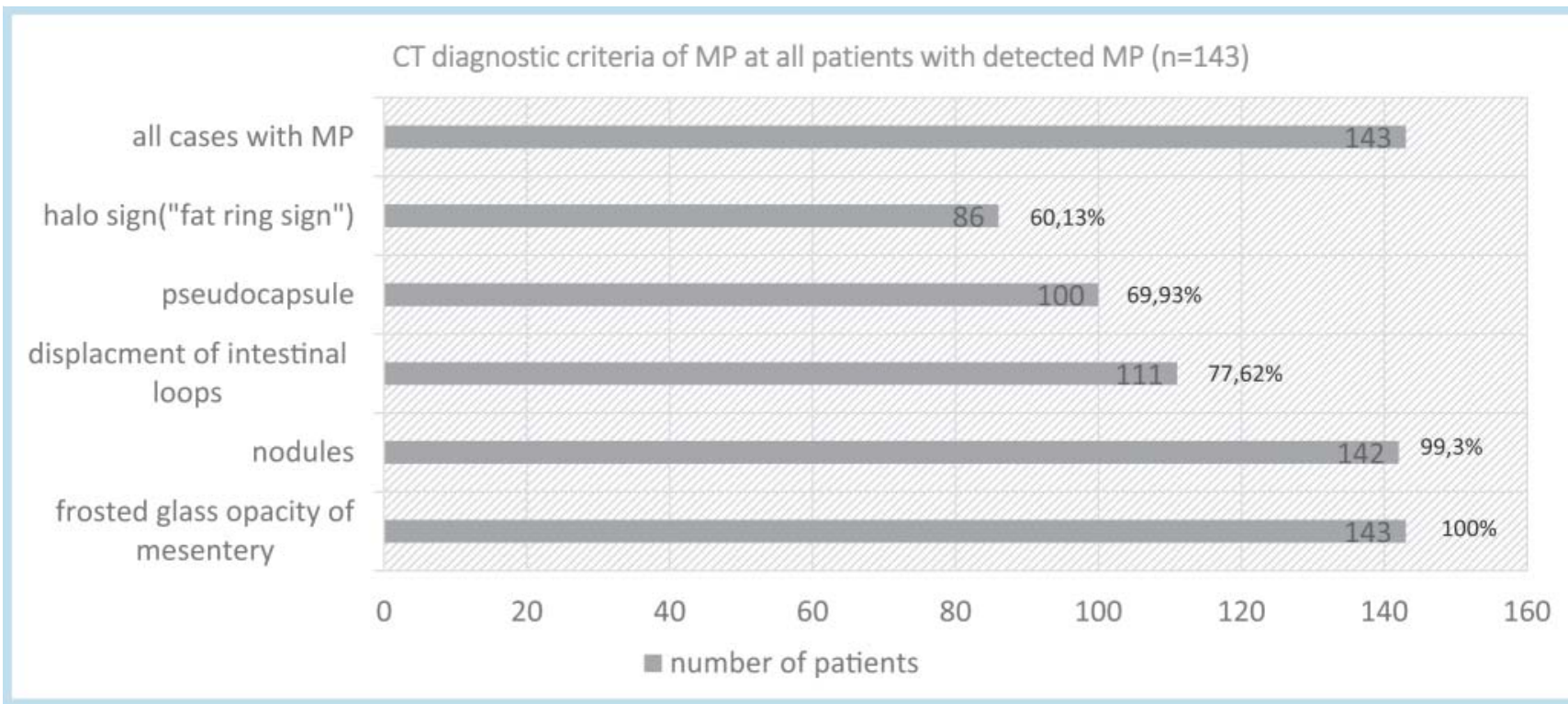

Fig. 3 Distribution of the diagnostic criteria for MP in the entire patient population.

Table 2 Frequency of different tumor entities in relation to the overall population as well as occurrence of MP with respect to the tumor entity.

\begin{tabular}{|c|c|c|c|c|c|c|}
\hline tumor entity & $\begin{array}{l}\text { frequency tumor| } \\
\text { overall population }\end{array}$ & $\%$ & $\begin{array}{l}\text { frequency MP/ } \\
\text { tumor entity }\end{array}$ & $\%$ & $\begin{array}{l}\text { frequency MP with } \\
\text { tumor/MP overall }\end{array}$ & $\%$ \\
\hline lymphoma & $128 / 5595$ & 2.26 & $29 / 128$ & 22.65 & $29 / 143$ & 20.27 \\
\hline colorectal cancer & $452 / 5595$ & 8.07 & $20 / 452$ & 4.42 & $20 / 143$ & 13.98 \\
\hline prostate cancer & $180 / 5595$ & 3.21 & $11 / 180$ & 6.11 & $11 / 143$ & 7.69 \\
\hline breast cancer & $262 / 5595$ & 4.68 & $5 / 262$ & 1.90 & $5 / 143$ & 3.49 \\
\hline pancreatic cancer & $64 / 5595$ & 1.14 & $7 / 64$ & 10.93 & $7 / 143$ & 4.89 \\
\hline gastric cancer & $110 / 5595$ & 1.96 & $5 / 110$ & 4.54 & $5 / 143$ & 3.49 \\
\hline renal cell carcinoma & $108 / 5595$ & 1.93 & $3 / 108$ & 2.77 & $3 / 143$ & 2.09 \\
\hline bronchial cancer & $126 / 5595$ & 2.25 & $7 / 126$ & 5.55 & $7 / 143$ & 4.89 \\
\hline bladder cancer & $79 / 5595$ & 1.41 & $5 / 79$ & 6.32 & $5 / 143$ & 3.49 \\
\hline melanoma & $44 / 5595$ & 0.78 & $2 / 44$ & 4.55 & $2 / 143$ & 1.39 \\
\hline esophageal cancer & $48 / 5595$ & 0.85 & $3 / 48$ & 6.25 & $3 / 143$ & 2.09 \\
\hline uterine cancer & $46 / 5595$ & 0.66 & $1 / 46$ & 2.17 & $1 / 143$ & 0.69 \\
\hline ovarian cancer & $84 / 5595$ & 1.50 & $1 / 84$ & 1.19 & $1 / 143$ & 0.69 \\
\hline other & $246 / 5595$ & 4.39 & $8 / 264$ & 3.25 & $8 / 143$ & 5.59 \\
\hline
\end{tabular}

$n=107 / 143$.

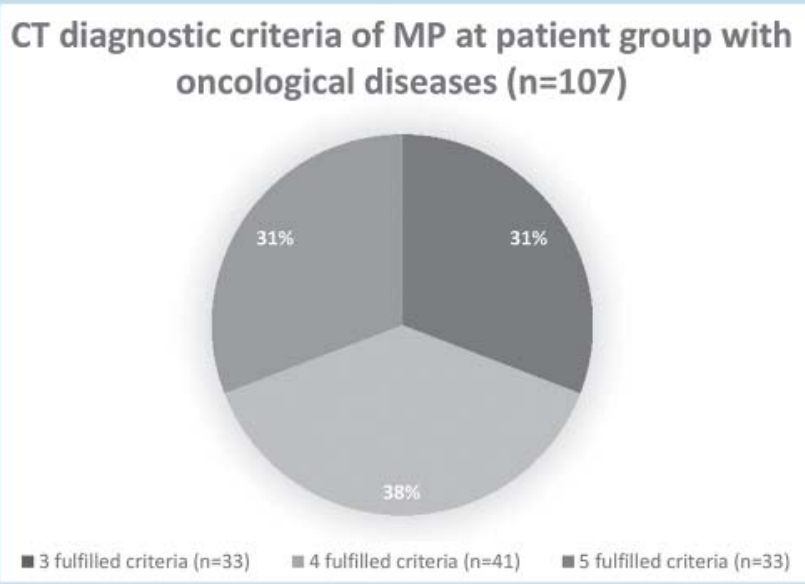

Fig. 4 Frequency of diagnostic criteria of MP in patient population with a tumor disease $(107 / 143)$.

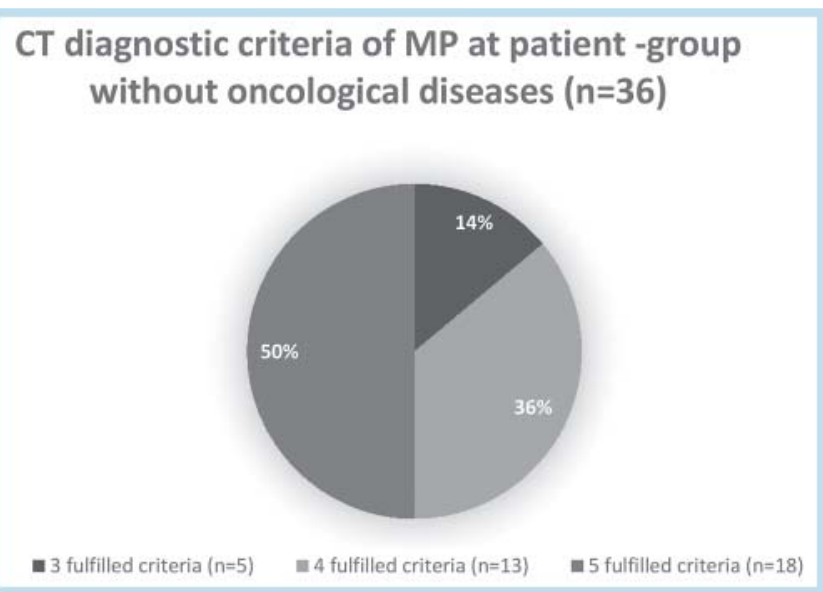

Fig. 5 Frequency of diagnostic criteria of MP in group of patients without a tumor disease (36/143). 


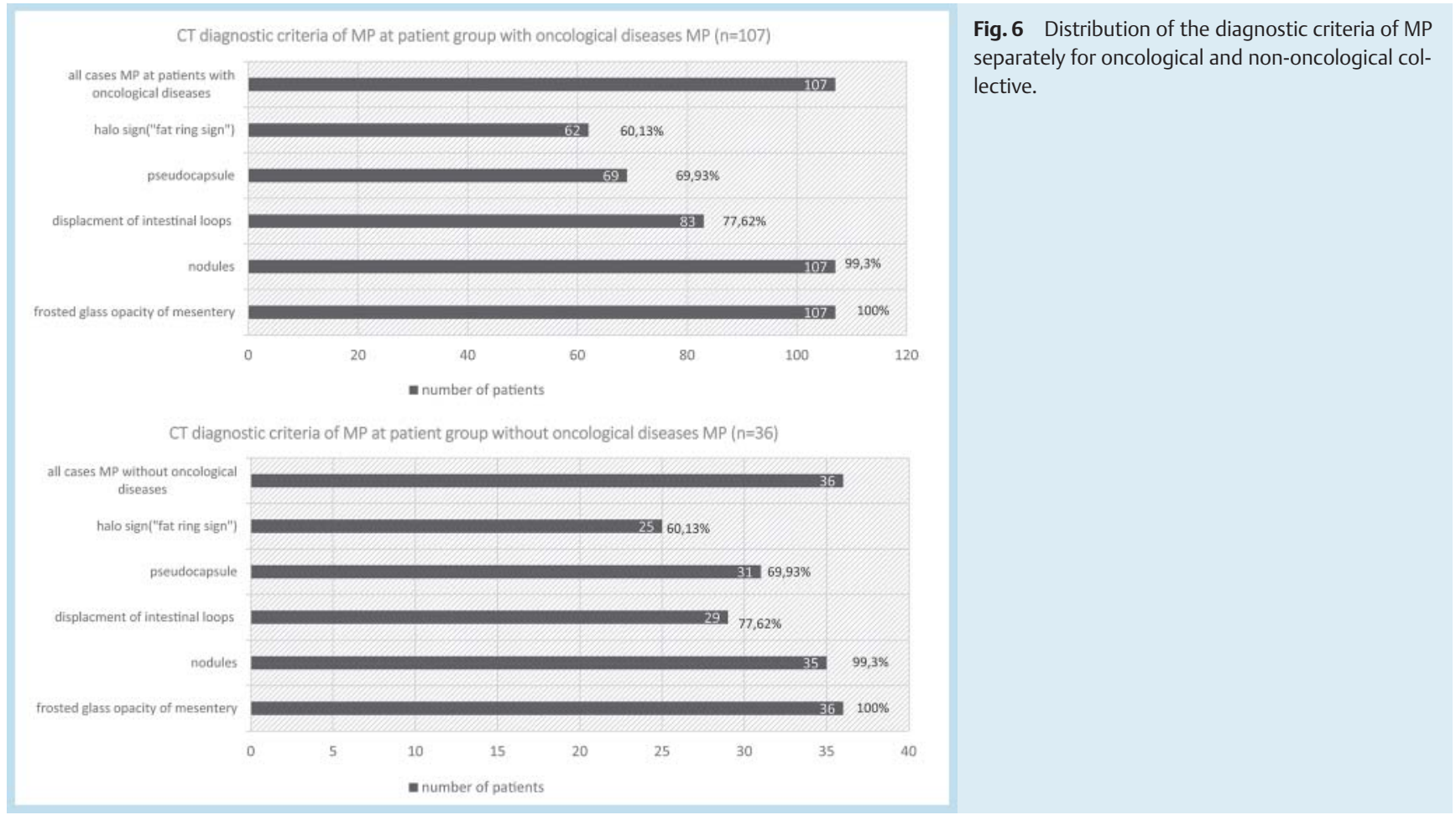

$(\mathrm{p}<0.001)$. The risk of MP increases with age by $24 \%$ per 10 years $(\mathrm{p}<0.02)$.

\section{Discussion \\ $\nabla$}

MP is typically an incidental CT finding in asymptomatic patients or is diagnosed during abdominal surgery [9, 14]. Important diagnostic criteria of MP in abdominal CT are increased density of the mesentery, a "fat-ring sign", a pseudocapsule, intercalated nodules, and displacement of the bowel loops. In the present study at least one diffuse increase in density of the affected mesentery with intercalated nodules was found in all patients with a diagnosis of MP. Intercalated nodules in the affected mesentery with an average size of less than $10 \mathrm{~mm}$ are observed in most patients $[10,15]$. Wilkes et al. postulated an increased risk for occult malignancy in nodules with a size of at least $12 \mathrm{~mm}$ and a lack of "fat-ring sign" or halo sign [1]. In our patient population $58 \%$ of cases of MP with an underlying oncological disease had a "fat-ring sign" or a halo sign, while the sign was seen in $69 \%$ of cases in the group of MP without tumor disease. A significant difference in nodule size in MP with and without tumor association was not seen in our cohort ( $\triangle$ Table 3 ). With a mean value of $-67 \mathrm{HU}$, the increase in density in the affected mesentery in our patient population was significantly higher compared to unaffected adipose tissue $(-109)$ and is comparable with the data in the literature [9, 10]. Displacement of adjacent bowel loops was identified in $77 \%$ of cases, a pseudocapsule in $70 \%$ of cases, and a "fat-ring sign" in $60.1 \%$ of cases. Studies by Daskalogianaki and Sabate showed similar results regarding the occurrence of a pseudocapsule and a "fat-ring sign" and describe changes that are useful for the differentiation from a lymphoma [5, 9]. The average thickness of a pseudocapsule is $3 \mathrm{~mm}[7,9,10]$. With respect to MP, the literature predominantly contains case reports. The frequency of MP is specified in the literature with a range from $0.16 \%$ to $7.83 \%$. In a prospective study including 7620 patients, Daskalogianaki et al. diagnosed MP in 49 patients $(0.6 \%)$. A retrospective study by Gögebakan et al. showed a similar prevalence $(0.58 \%$ of a total of 13485 patients) [10]. The lowest prevalence for MP is seen in a New Zealand study: $0.16 \%$ of the study population over a period of 8 years [1]. A limit of the study design of Gögebakan et al. and Wilkes et al. is the use of a keywordbased search method to search for MP in databases. Kuhrmeier identified mesenteric lipodystrophy with typical macroscopic and histopathological changes of the mesenteric adipose tissue in 9 of 712 autopsies (1.26\%) [16]. In a prospective evaluation of CT scans of 613 patients, the workgroup of Coulier showed a prevalence of $7.83 \%$. They postulated that the reason for this higher prevalence of MP compared to earlier studies could be explained by advances in CT technology with the increasing use of multidetector CT [8]. Canyigit et al. published a prevalence of $2.43 \%$ in 2100 retrospectively evaluated patients [7].

In the present study, 143 cases of MP in a retrospectively evaluated cohort of 5595 patients (2.55\%) were identified. There was a histopathologically confirmed malignancy in 107 of these 143 cases (74.8\%). Therefore, in our cohort MP occurred significantly more frequently in the presence of an oncological disease. The most common tumor entity associated with MP in our patient population was nonHodgkin lymphoma (NHL). Daskalogianaki et al. described a concomitant oncological disease in 34 patients with MP (69.3\%). NHL was the most frequently seen malignant disease associated with MP [9]. Wilkes et. al identified a tumor association in $38 \%$ of MP cases. The most common tumor entity in this study was colorectal cancer followed by 


\begin{tabular}{|c|c|c|c|c|c|c|}
\hline & number & $\begin{array}{l}\text { mesentery with } \\
\text { milk-glass } \\
\text { appearance } \\
\text { [\%] }\end{array}$ & $\begin{array}{l}\text { number of } \\
\text { nodules [\%] } \\
\emptyset\end{array}$ & $\begin{array}{l}\text { "fat-ring sign" } \\
\text { or halo sign }\end{array}$ & pseudocapsule & $\begin{array}{l}\text { space-occu- } \\
\text { pying effect }\end{array}$ \\
\hline NHL & $\begin{array}{l}29 / 128 \\
(22.6 \%)\end{array}$ & $\begin{array}{l}29 / 29 \\
(100 \%)\end{array}$ & $\begin{array}{l}29 / 29 \\
(100 \%) \\
8.01 \mathrm{~mm}+/-4.33 \\
3-15 \mathrm{~mm}\end{array}$ & $\begin{array}{l}12 / 29 \\
(41 \%)\end{array}$ & $\begin{array}{l}17 / 29 \\
(58.6 \%)\end{array}$ & $\begin{array}{l}20 / 29 \\
(68.9 \%)\end{array}$ \\
\hline colorectal cancer & $\begin{array}{l}20 / 452 \\
(4.4 \%)\end{array}$ & $\begin{array}{l}20 / 20 \\
(100 \%)\end{array}$ & $\begin{array}{l}20 / 20 \\
(100 \%) \\
7.45 \mathrm{~mm}+/-4.08 \mathrm{~mm} \\
3-15 \mathrm{~mm}\end{array}$ & $\begin{array}{l}10 / 20 \\
(50 \%)\end{array}$ & $\begin{array}{l}12 / 20 \\
(60 \%)\end{array}$ & $\begin{array}{l}13 / 20 \\
(65 \%)\end{array}$ \\
\hline prostate cancer & $\begin{array}{l}11 / 180 \\
(6.1 \%)\end{array}$ & $\begin{array}{l}11 / 11 \\
(100 \%)\end{array}$ & $\begin{array}{l}11 / 11 \\
(100 \%) \\
8.54 m m+/-4.08 m m \\
3-15 m m\end{array}$ & $\begin{array}{l}7 / 11 \\
(63.3 \%)\end{array}$ & $\begin{array}{l}7 / 11 \\
(63.3 \%)\end{array}$ & $\begin{array}{l}8 / 11 \\
(72.7 \%)\end{array}$ \\
\hline bronchial cancer & $\begin{array}{l}7 / 64 \\
(5.5 \%)\end{array}$ & $\begin{array}{l}7 / 7 \\
(100 \%)\end{array}$ & $\begin{array}{l}7 / 7 \\
(100 \%) \\
8.5 \mathrm{~mm}+/-4.51 \mathrm{~mm} \\
3-15 \mathrm{~mm}\end{array}$ & $\begin{array}{l}5 / 7 \\
(71.4 \%)\end{array}$ & $\begin{array}{l}7 / 7 \\
(100 \%)\end{array}$ & $\begin{array}{l}7 / 7 \\
(100 \%)\end{array}$ \\
\hline pancreatic cancer & $\begin{array}{l}7 / 64 \\
(10.9 \%)\end{array}$ & $\begin{array}{l}7 / 7 \\
(100 \%)\end{array}$ & $\begin{array}{l}7 / 7 \\
(100 \%) \\
7.28+/-4.26 \mathrm{~mm} \\
3-15 \mathrm{~mm}\end{array}$ & $\begin{array}{l}5 / 7 \\
(71.4 \%)\end{array}$ & $\begin{array}{l}5 / 7 \\
(71.4 \%)\end{array}$ & $\begin{array}{l}6 / 7 \\
(85.7 \%)\end{array}$ \\
\hline $\begin{array}{l}\text { non-oncological } \\
\text { group }\end{array}$ & $\begin{array}{l}36 / 3621 \\
(0.99 \%)\end{array}$ & $\begin{array}{l}36 / 36 \\
(100 \%)\end{array}$ & $\begin{array}{l}36 / 36 \\
(100 \%) \\
7.5 \mathrm{~mm}+/-3.71 \mathrm{~mm} \\
3-15 \mathrm{~mm}\end{array}$ & $\begin{array}{l}25 / 36 \\
(69.4 \%)\end{array}$ & $\begin{array}{l}31 / 36 \\
(86.1 \%)\end{array}$ & $\begin{array}{l}29 / 36 \\
(80.5 \%)\end{array}$ \\
\hline
\end{tabular}

lymphoma [1]. Canyigit et al. and Akram et al. described a relatively low association between MP and a malignant disease (17.6\% and $13 \%$, respectively) [6, 7]. In the retrospective case-control study by Gögebakan et al., a concomitant tumor disease was detected in $50.6 \%$ of patients with MP-related changes. The majority of these cases were categorized as mild and moderate according to Coulier. More patients in the control group had a malignant disease (61.2\%). No significant relationship between tumor disease and the occurrence of MP was determined based on the data of this cohort [10]. In our cohort with a tumor disease (1974), 107 patients showed MP-related changes. In the patient group without a tumor disease (3621), 36 cases of MP were diagnosed. The prevalence for MP in the oncological group $(5.7 \%)$ was significantly higher than in the group without a tumor disease (1\%). In our patient population, NHL was associated with MP in 29 cases, comprising $22.6 \%$ of our lymphoma patients. Colorectal, bronchial, prostate and pancreatic cancers were also often associated with MP ( $\odot$ Table 3 ). An association of MP with lymphoma, particularly non-Hodgkin lymphoma, has also been described in previous studies $[6,9,17,18]$. The extent to which MP is a reaction to an already present malignancy or is merely an incidental finding without an association with a tumor disease is unclear. The literature is divided with respect to the relationship between MP and malignancies. The pathogenesis of MP in tumor diseases is also unclear and controversial. Kipfer et al. postulated that MP is a nonspecific reaction to an abdominal malignancy [19]. Although the results of the study by Daskalogiannaki et al. could not confirm this thesis since $55.8 \%$ of the MP patients in their cohort had a tumor in an extraabdominal lo- cation, they did confirm the hypothesis of MP as a predictor for a malignancy since $69.4 \%$ of the patients with MP had a tumor disease [9]. Wilkens et al. formulated the thesis of MP as a possible paraneoplastic syndrome in the case of a tumor disease [1]. Our cohort also confirms the theory of MP as a predictor of tumor disease since $74.8 \%$ of MP patients had a tumor disease. A typical constellation of MP features that reliably indicates tumor disease or a non-neoplastic genesis cannot be determined from our data. On the whole, we observed the "fat-ring sign" or the halo sign and psuedocapsule formation more frequently in the non-oncological group ( $\odot$ Table 3 ). MP is predominantly observed in older patients in the 6th-7th decade of life. MP seems to occur predominantly in males with a male to female ratio of $2: 1[6,7,20]$. A maximum occurrence in the 6th-7th decade of life and a male to female ratio of 2:1 were also seen in our cohort. This high average age could be a limitation of our cohort since there is already an increased risk for a tumor disease with increasing age [10]. A relatively low number of patients in the large cohort had MP. However, due to the retrospective analysis of all CT data sets, it is possible to provide complete representation of the prevalence in our cohort. MP can be reliably diagnosed on a purely morphological basis under consideration of the diagnostic criteria [10, 11, 21]. A keywordbased database search may include the error of incorrectly low diagnosis of MP since some authors consider MP underdiagnosed [17, 20]. Since different MP triggers have been discussed $[6,7,9,11,22-25]$, the diagnosis of MP should not necessarily result in escalation of the diagnosis to possible tumor disease but rather should be discussed in light of the potential risk. 


\section{References}

1 Wilkes A, Griffin N, Dixon L et al. Mesenteric panniculitis: a paraneoplastic phenomenon? Dis Colon Rectum 2012; 55: 806-809

2 George V, Tammisetti VS, Surabhi VR et al. Chronic Fibrosing Conditions in Abdominal Imaging. Radio Graphics 2013; 33: 1053-1080

3 Horton KM, Lawler LP, Fishman EK. CT findings in sclerosing mesenteritis (panniculitis): spectrum of disease. Radiographics 2003; 23: $1561-1567$

4 Issa I, Baydoun H. Mesenteric panniculitis: various presentations and treatment regimens. World J Gastroenterol 2009; 15: 3827-3830

5 Sabaté JM, Torrubia S, Maideu J et al. Sclerosing Mesenteritis: Imaging Findings in 17 Patients. Am J Roentgenol 1999; 172: 625 -629

6 Akram S, Pardi DS, Schaffner JA et al. Sclerosing mesenteritis: clinical features, treatment, and outcome in ninety-two patients. Clin Gastroenterol Hepatol 2007; 5: 589-596

7 Canyigit M, Koksal A, Akgoz A et al. Multidetector-row computed tomography findings of sclerosing mesenteritis with associateddiseases and its prevalence. Japanese Journal of Radiology 2011; 29: 495 -502

8 Coulier B. Mesenteric panniculitis. Part 2: prevalence and natural course: MDCTprospective study. JBR-BTR 2011; 94: 241 - 246

9 Daskalogiannaki M, Voloudaki A, Prassopoulos P et al. CT Evaluation of mesenteric panniculitis: prevalence and associated diseases. Am J Roentgenol 2000; 174: 427-431

10 Gögebakan Ö, Albrecht T, Osterhoff MA et al. Is mesenteric panniculitis truely a paraneoplastic phenomenon? A matches pair analysis. Eur J Radiol 2013; 82: 1853 - 1859

11 Vlachos K, Archontovasilis F, Falidas E et al. Sclerosing Mesenteritis: Diverse clinical presentations and dissimilar treatment options. A case series and review oft he literature. Int Arch Med 2011; 4: 17

12 McLaughlin PD, Filippone A, Maher MM. The "misty mesentery": mesenteric panniculitis and its mimics. Am J Roentgenol 2013; 200: $116-123$

13 Okino Y, Kiyosue H, Mori $\mathrm{H}$ et al. Root of the small-bowel mesentery: correlative anatomy and CT features of pathologic conditions. Radiographics $2001 ; 21: 1475-1490$
14 Khachaturian T, Hughes J. Mesenteric panniculitis. West J Med 1988; 148: $700-701$

15 Scheer F, Spunar P, Andresen R. Persistierende mesenteriale Pannikulitis nach Cholezystektomie bei chronischer Cholezystitis. Fortschr Röntgenstr 2016; 188: 98-91

16 Kuhrmeier A. Mesenteric lipodystrophy. Schweiz Med Wochenschr 1985; $115: 1218-1224$

17 Ogden WW, Bradburn DM, Rives JD. Mesenteric panniculitis: Review of 27 Cases. Ann Surg 1965; 161: 864-875

18 Hiridis S, Hadgigeorgiou R, Karakitsos $D$ et al. Sclerosing mesenteritis affecting the small and the large intestine in a male patient with nonHodgkin lymphoma: a case presentation and review of the literature. J Med Case Rep 2008; 17: 388

19 Kipfer RE, Moertel CG, Dahlin DC. Mesenteric lipodystrophy. Ann Intern Med 1974; 80: $582-588$

20 Nicholson JA, Smith D, Diab M et al. Mesenteric panniculitis in Merseyside: a case series and a review of the literature. Ann R Coll Surg Engl 2010; 92: $31-34$

21 Gunduz Y, Tatli AP, Kara RO. Mesenteric panniculitis: a case report and review of the literature. Maedica (Buchar) 2012; 7: 344-347

22 Cakmak O, Tanyel FC, Cağlar M et al. Mesenteric panniculitis mimicking acute abdomen in a 4-year-old child. Z Kinderchir 1986; 41: 313-314

23 Minato $\mathrm{H}$, Shimizu J, Arano $Y$ et al. IgG4-related sclerosing mesenteritis: a rare mesenteric disease of unknown etiology. Pathol Int 2012; 62: $281-286$

24 Stone JH, Khosroshahi A, Deshpande V et al. Recommendations for the nomenclature of IgG4-related disease and its individual organ system manifestations. Arthritis Rheum 2012; 64: 3061 - 3067

25 Rumman N, Rumman G, Sharabati B et al. Mesenteric panniculitis in a child misdiagnosed as appendicular mass: a case report and review of literature. SpringerPlus 2014; 3: 73

26 Ege G, Akman H, Cakiroglu G. Mesenteric panniculitis associated with abdominal tuberculous lymphadenitis: a case report and review of the literature. Br J Radiol 2002; 75: 378 - 380 